Geological Society, London, Special Publications

\title{
Lower crustal rheological expression in inverted basins
}

Mike Sandiford, David L. Hansen and Sandra N. McLaren

Geological Society, London, Special Publications 2006, v.253; p271-283.

doi: 10.1144/GSL.SP.2006.253.01.14

Email alerting service

Permission request

Subscribe click here to receive free e-mail alerts when new articles cite this article

click here to seek permission to re-use all or part of this article

click here to subscribe to Geological Society, London, Special Publications or the Lyell

Collection

\section{Notes}




\title{
Lower crustal rheological expression in inverted basins
}

\author{
MIKE SANDIFORD ${ }^{1}$, DAVID L. HANSEN ${ }^{2}$ \& SANDRA N. MCLAREN ${ }^{3}$ \\ ${ }^{1}$ School of Earth Sciences, University of Melbourne, Victoria, 3010, Australia \\ (e-mail:mikes@unimelb.edu.au) \\ ${ }^{2}$ Department of Earth Sciences, University of Aarhus, Finlandsgade 6-8, \\ DK-8200, Aarhus, Denmark \\ ${ }^{3}$ Research School of Earth Sciences, Australian National University, ACT, Australia
}

\begin{abstract}
Although lithospheric modelling has provided extraordinary insights into the processes that shape the continental crust, considerable uncertainty surrounds the basic rheology that governs behaviour at geological timescales. In part, this is because it has proved difficult to identify the geological observations that might discriminate, or unify, models of lithospheric rheology. In particular, the relative strength of lower crust and upper mantle remains a contentious aspect of continental lithospheric rheology. We show that various models for lower crustal rheology may produce distinct patterns of inversion in extensional sedimentary basins, consistent with some of the observed natural variability of inversion styles. Inversion of basin interiors, as is common in European Mesozoic basins, is favoured by a lithospheric rheology more sensitive to lateral thermal structure than to changes in the depth of the Moho, consistent with there being little strength contrast between the lower crust and upper mantle in these settings. In contrast, inversion of basin margins, particularly involving basinward verging structures, is consistent with a rheological sensitivity to the depth of Moho as would apply for a lower crust much weaker than the upper mantle. We use an example from central Australia to demonstrate this latter response, together with thermochronologic data that suggests that a relatively weak lower crust in this setting may reflect abnormally high geothermal gradients.
\end{abstract}

At the continental scale, meaningful predictions about the length-scales of deformation have been derived from models treating the lithosphere in terms of vertically averaged rheology (England \& Houseman 1986). While these provide an important framework for understanding the long-wavelength deformation of continental interiors they do not provide much insight into the geometry of deformation at sub-lithospheric scales, where a more explicit treatment of the rheological and compositional stratification of the lithosphere is required (e.g., Beaumont et al. 2000). There is general consensus that rheological stratification of the lithosphere arises because of competition between pressure- and temperature-sensitive deformation mechanisms on the one hand, and compositional and mineralogical stratification of the lithosphere on the other (Brace \& Kholstedt 1980). However, the distribution of strength remains controversial (Jackson 2002; Afonso \& Ranalli 2004), as is the extent to which the strength distribution imposes on the resulting distribution of strain.

The Moho is the most important compositional boundary within the lithosphere, with the associated density contrast providing a fundamental control on the mechanics of crustal deformation. In many rheological models the strength contrast across the Moho (from weak lower crust to strong mantle) is so strongly expressed that the depth (and temperature) of the Moho is the dominant parameter controlling the rheological response of the lithosphere (Sonder \& England 1986). This so-called 'jelly sandwich' model has been questioned (Jackson 2002) because it appears at odds with observations that imply that the lower crust is seismically active and capable of sustaining elastic stresses over geological timescales (Maggi et al. 2000). Indeed, Jackson (2002) has argued that the lower crust may be as strong as, if not stronger than, the upper mantle beneath, with the implication that the Moho has little relevance to the mechanical behaviour of the continental lithosphere (Fig. 1).

In numerical simulations, we might expect that the 'jelly sandwich' and 'stiff crust' (endmember) rheologies lead to qualitative differences in the styles and patterns of lithospheric deformation, especially for regions characterized by lateral variations in crustal thickness and 
(a) the 'jelly sandwich'

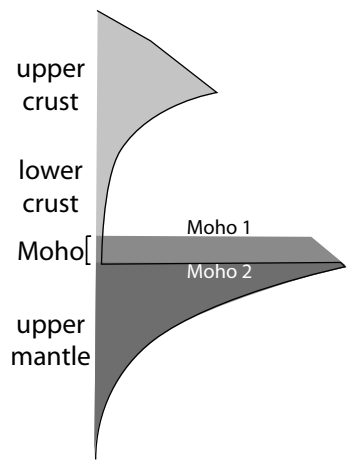

(b) the 'stiff crust'

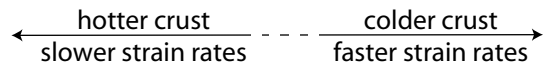

Fig. 1. Schematic illustration of vertical distribution of strength (at depth independent strain rate) in the (a) 'jelly sandwich' and (b) 'stiff crust' rheological models. An important difference between these models is the greater sensitivity of the 'jelly sandwich' rheology to the depth of the Moho, as indicated by the effect of changing Moho depth (i.e., Moho 1 to Moho 2) on the vertically integrated strength (i.e., the area under a given strengthdepth profile). Such hypothetical models are sensitive to the geothermal and strain rate regimes.

thermal regime. The objective of this paper is to explore such qualitative differences by using forward numerical models for the inversion of extensional sedimentary basins. The classic setting showing such lateral structure is old, extended continental crust where the isostatic response to stretching has resulted in the development and filling of sedimentary basins (McKenzie 1978). Here, we consider the way inversion operates on thermally equilibrated extended lithosphere, adopting the assumption that sufficient time has elapsed since extension that all thermal transients associated with the extensional deformation and basin-filling have dissipated.

Many factors have been postulated to influence the style inversion of sedimentary basins, as evidenced by the extensive body of literature dedicated to this very subject (e.g., Cooper \& Williams 1989; Buchanan \& Buchanan 1995; Turner \& Williams 2004). Our objective here is not to provide a comprehensive assessment of all factors that contribute to, and control, inversion, but rather to explore how the two endmember lower crustal rheologies might express themselves in terms of inversion styles. Thus we make a number of simplifying assumptions such as ignoring the anisotropy introduced by basin-forming faulting. This helps to isolate the specific consequences of differing lower crustal rheology and is not meant to imply that these other factors are not equally, if not more, important.

Of course, it is important to evaluate the results of forward models against observations from the real world, and so we begin with some basic observations pertinent to variability in the style of basin inversion in nature. This is followed by an analysis of simple thermomechanical models of basin evolution using the end-member rheologies that reproduce some of the essential elements of this natural variation. As summarized by Turner \& Williams (2004), a particular problem highlighted in previous analyses of basin inversion has been the mechanical problem of inverting basin interiors where the lithosphere is assumed to have been strengthened by isostatically compensated reductions in Moho depth. This study directly relates to this problem, with our analysis suggesting that, to a large degree, the variation of inversion styles observed in nature may be explicable in terms of variability in lower crustal rheological state.

\section{Styles of inversion in nature}

In nature there is a significant variation in the style and distribution of inversion within inverted basins (e.g., Turner \& Williams 2004). Here we make some brief remarks about two distinct styles of inversion relevant to our later analysis of numerical modelling results.

The classic style of basin inversion, as evident in numerous examples from Europe (Fig. 2) is characterized by a central zone of basin floor uplift and intense deformation accommodated by reverse faults. The inverted zones coincide with the depocentres of the precursor rift basin and as such the deeper sediments experienced the most uplift. The basin flanks typically subsided and syn-inversion marginal troughs developed. The latter effect reflects the flexural isostatic response to the crustal thickening of the inversion zones (Nielsen \& Hansen 2000). In Europe, in the Alpine foreland, the marginal troughs are consistently filled with late Cretaceous chalks, of which only a small fraction is reworked material, signalling the relative simultaneity of the main compressive inversion phases. Here, the time interval between basin formation and inversion is largely set by the phases of rifting, relating to the Mesozoic break-up of Pangea, and the phases of Late Cretaceous and Cenozoic compression relating to the collision of the African and European plates. As this time interval generally compares to the lithospheric thermal time constant, the localization 

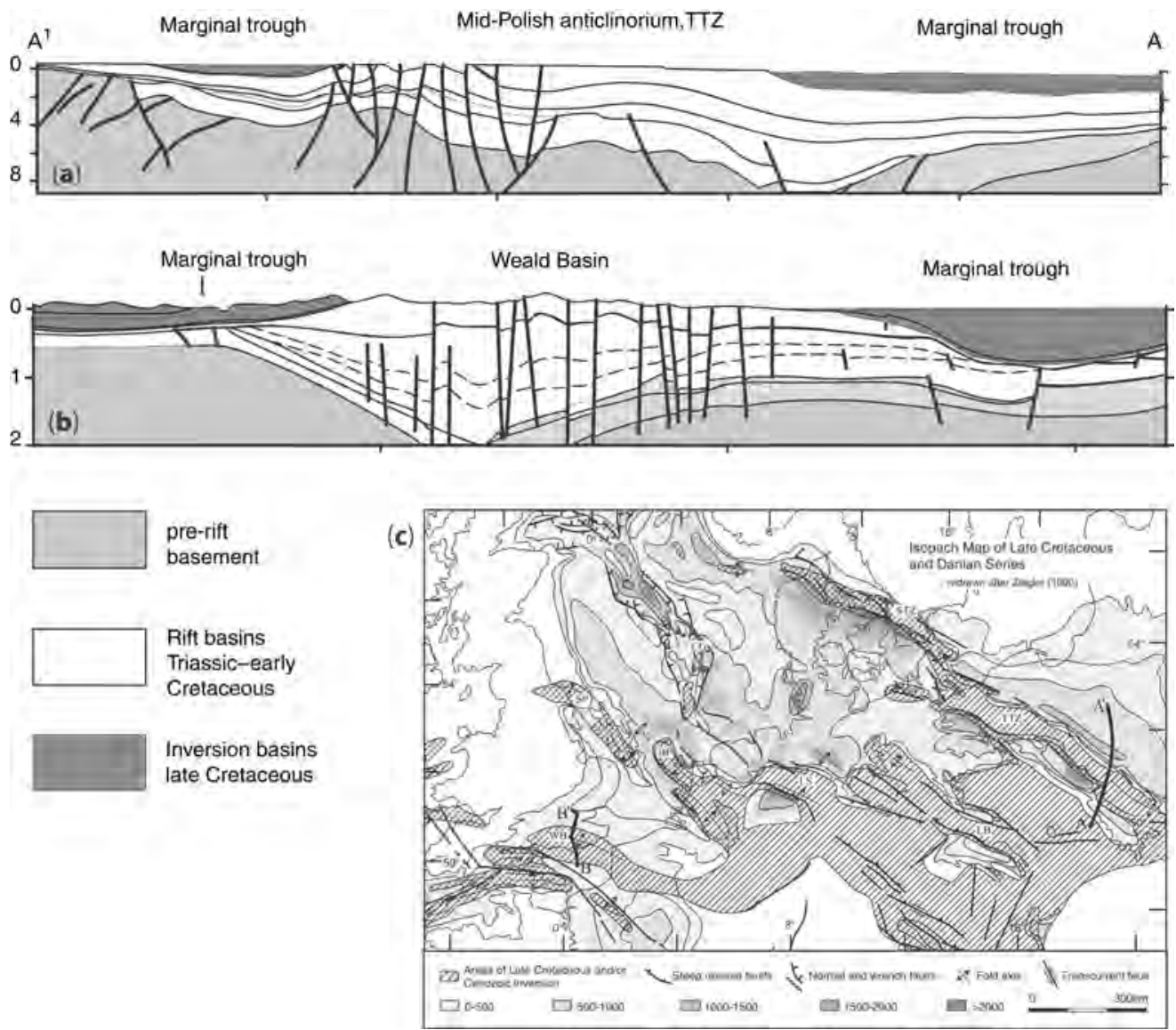

Fig. 2. Cross-section of typical inverted basins (upper panel: Polish trough c. $230 \mathrm{~km}$ across; lower panel: Weald Basin, SE England, c. $160 \mathrm{~km}$ across), adapted from Nielsen \& Hansen (2000). The locus of maximum inversion intensity typically occurs in the interior of the precursor rift basins. During inversion reworked sediment is shed to marginal troughs that extend across the precursor basin margin towards the foreland. In these cases, inversion occurred at time intervals that preclude localization due to thermal transients associated with the initial rifting. In the case of the Polish Trough, rifting took place from $255 \mathrm{Ma}$ to $152 \mathrm{Ma}$ while the inversion occurred from $85 \mathrm{Ma}$ to $55 \mathrm{Ma}$. For the Weald Basin, rifting took place from $210 \mathrm{Ma}$ to $130 \mathrm{Ma}$ and inversion from $60 \mathrm{Ma}$ 13. TTZ: Tornquist-Teisseyre zone.

of deformation during inversion cannot be attributed to the thermal perturbations associated with the earlier rifting.

Palaeozoic inverted basins in central Australia show a rather different style of inversion (Fig. 3). Central Australia comprises a mosaic of structurally remnant Neoproterozoic basins initiated at around $800 \mathrm{Ma}$ (e.g., Amadeus, Officer, Georgina and Ngalia basins). These basins are typically several hundred kilometres wide and bounded by basin verging structures that formed at various times through the Palaeozoic, many hundreds of million years after initial basin formation. These inversion structures now expose basement-cored Proterozoic gneissic complexes in their hanging wall (Figs 3 and 4).
The distribution of sediment fill and underlying causes controlling the distribution of Neoproterozoic depocentres in the primary basins has been the subject of controversy warranting some discussion of their geodynamic setting. To this end we briefly summarize some salient ideas about these basins. The interested reader can find more comprehensive accounts in Lambeck (1983), Lindsay et al. (1987), Korsch and Lindsay (1989), Lindsay and Korsch (1991), Shaw et al. (1991), Walter and Gorter (1994), Walter et al. (1995) and Sandiford et al. (2001).

In one of the earliest accounts (Lambeck 1983) the formation of the central Australia basins was attributed to long high amplitude $(c .10 \mathrm{~km})$ lithospheric-scale buckling, largely on the basis of the 

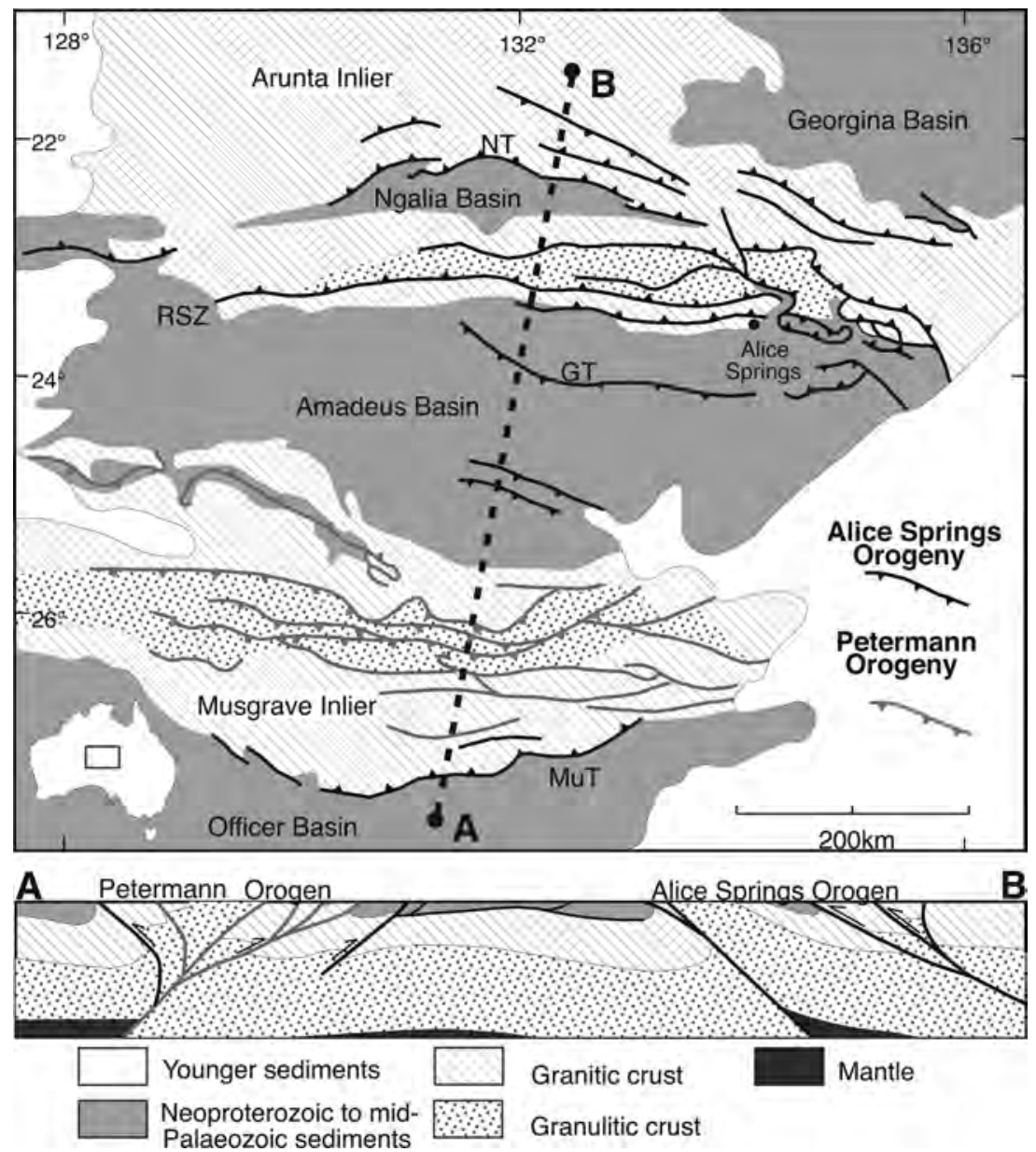

Fig. 3. Geological map of the central Australian region, showing the structurally remnant Neoproterozoic basins (the Officer, Amadeus, Ngalia and Georgina Basins), separated by basement inliers (the Musgrave and Arunta Inliers), adapted from Sandiford et al. (2001). Within the basement inliers we can distinguish two distinct types of terrane: (1) gneissic granite terranes that form the peripheral regions of the inliers and which are unconformably overlain by the sediments in the basins; (2) depleted granulite terranes that define the cores of the inliers and which are tectonically juxtaposed with the gneissic granite terranes. This juxtaposition reflects, in part, the strain associated with intraplate orogeny accumulated during the exhumation of the basement inliers from beneath a formerly more or less continuous intracratonic basin. In the Arunta Inlier this intraplate deformation was principally associated with the 450-300 Ma Alice Springs Orogeny, while in the Musgrave Inlier it was associated with the 550-500 Ma Petermann Orogeny. GT: Gardiner Thrust; MuT: Munyari Thrust; NT: Napperby Thrust; RSZ: Redbank Shear Zone.

distinctive gravity pattern of the region (see also Stephenson \& Cloetingh 1991). However, subsequent workers (e.g., Teyssier 1985) have demonstrated that the gravity pattern largely reflects late structuring of the basin during inversion (Shaw et al. 1991; Sandiford 2002) and therefore does not provide an unequivocal constraint on the earlier basin-forming process. Consequently almost all subsequent analyses have emphasized the role of extensional processes in basin formation (e.g., Lindsay et al. 1987;
Korsch \& Lindsay 1989; Shaw et al. 1991; Walter \& Gorter 1994; Walter et al. 1995; Sandiford et al. 2001). The current consensus is that the main rifting associated with basininitiation stage occurred at $>800 \mathrm{Ma}$. Subsidiary, milder extensional episodes are reflected in changes in the depocentres up until the early Ordovician (e.g., Shaw et al. 1991). Relatively new data from sediment provenance studies (Comacho et al. 2002) shed important further light on the original extent of these extensional 
basins. These data demand proximal exposure of basement throughout basin evolution (implying that the present-day distribution of structurally remnant basins mirrors the original pattern of extensional basins). Moreover, from the point of view of our analysis, the findings of Comacho et al. (2002) imply that the style of inversion in central Australia must have involved marginal inversion, rather than inversion along a central basin axis as typifies the European Mesozoic basins, with the sediment generated during inversion redistributed towards the original basin centres. Further, the basin-verging asymmetry of the main structures that accommodate basin inversion in central Australia makes them geometrically incompatible with reactivation of plausible primary basin forming, extensional structures that would be expected to dip southwards towards the basin interior (Fig. 4). This is an important inference, since it implies that the existence of basin-forming structures is not likely to be the primary determinant in localizing crustal shortening during inversion in this setting. However, it is necessary to provide a word of caution about this interpretation since the geometry of the primary, basin-forming structures in central Australia is not well understood. This is partly due to the intensity of the subsequent inversion in which large thrust sheets and nappe structures developed as part of a crustal-scale deformation event (e.g., Teyssier 1985; Golbey et al. 1989; Sandiford 2002), thereby obscuring earlier formed structures.

One potentially important distinction between the European and Australian basins may relate to the crustal thermal regime at the time of inversion. Heat flows in the Tornquist zone in the Polish Basin (Fig. 2a) are c. $65-70 \mathrm{mWm}^{-2}$ (Balling 1995), which are only slightly greater than average continental crustal heat flows. Unfortunately heat flow data from central Australia is sparse, with no available data from the central Australian basins. However, the central Australian crust on which the basin is formed is characterized by unusually high radiogenic element concentrations (Sandiford et al. 2001, Fig. 4), as is much of the Australian Proterozoic, where the average heat flow is $85 \mathrm{mWm}^{-2}$ (see McLaren et al. 2003 for a full account). Bottom-hole temperatures from exploration wells in the northern half of the Amadeus Basin suggest modern-day thermal gradients of c. $25^{\circ} \mathrm{C} / \mathrm{km}$ and locally as high as $35^{\circ} \mathrm{C} / \mathrm{km}$ (Gorter 1984). Using our own unpublished thermal conductivity data (which yield average basin sediment conductivities of $c .2 .7 \mathrm{~W} / \mathrm{m} / \mathrm{K}$ ), these thermal gradients are consistent with heat flows of $c .65-95 \mathrm{mWm}^{-2}$. The existence of

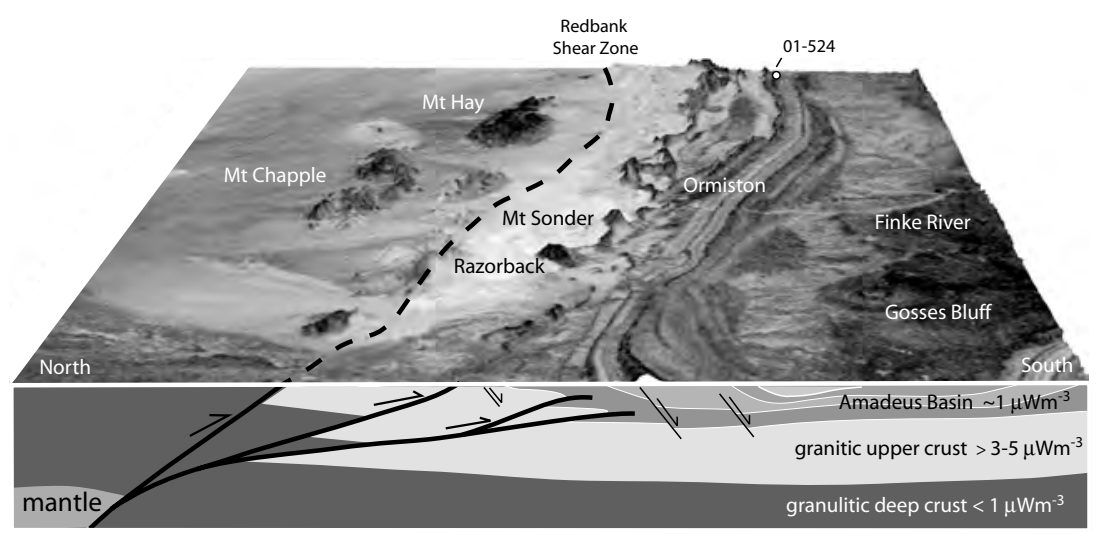

Fig. 4. Airborne radiometric image, data courtesy of Northern Territory Geological Survey, draped over a digital elevation model of the western Macdonnell ranges along the inverted boundary between the Arunta Inlier and the Amadeus basin, with crustal scale cross-section showing the main crustal elements associated with Proterozoic basin formation and Palaeozoic inversion. Note the basin-verging (southward) inversion structures associated with the Redbank shear zone (thick black lines) are geometrically incompatible with the schematically illustrated basin-forming structures (thin black lines). Sample site 01-524 shows the location of the K-feldspars used to constrain thermal regimes during basin inversion. In terms of radioelement concentrations, three distinct elements can be identified (Sandiford et al. 2002): (1) the sediments of the Amadeus basin that have heat production rates of $c .1 \mu \mathrm{Wm}^{-3}$, (2) the granites and gneisses that immediately underlie the Amadeus Basin and have heat production rates of $>3 \mu \mathrm{Wm}^{-3}$ (locally up to c. $10 \mu \mathrm{Wm}^{-3}$ ), and (3) the deep crustal mafic granulites that outcrop as isolated monadnocks (e.g., Mount Chapple and Mount Hay) in the desert to the north of the Redbank shear zone with heat production rates $<1 \mu \mathrm{Wm}^{-3}$. 
elevated thermal gradients in the central Australian basins prior to inversion is implied by thermochronological data of detrital K-feldspar from a granite boulder in glaciogenic sediments in the lower part of the basin (Fig. 5a). These data (are available online at http://www. geolsoc.org.uk/SUP18240. A hardcopy can be obtained from the Society Library.) show partial resetting of ${ }^{40} \mathrm{Ar} /{ }^{39} \mathrm{Ar}$ spectra and are believed to reflect the thermal conditions representative of the northern margin of the basin (see Appendix 1 for further elaboration). Importantly, the preservation of pre-basin formation ${ }^{40} \mathrm{Ar} /{ }^{39} \mathrm{Ar}$ ages (up to $1100 \mathrm{Ma}$ ) implies that temperatures never exceeded $c .230^{\circ} \mathrm{C}$ during the evolution of this part of the basin (i.e., in the interval 400-800 Ma). Similarly, the fact that the partial resetting of the ${ }^{40} \mathrm{Ar} /{ }^{39} \mathrm{Ar}$ spectra has demonstrably occurred during the basin-forming interval requires that temperatures must have exceeded $150^{\circ} \mathrm{C}$ (Fig. 5). Albeit subject to somewhat contentious vagaries of the method, our modelling of the spectra achieves best fits with peak temperatures in the range $170-190^{\circ} \mathrm{C}$ at the time when inversion commenced (c. $400 \mathrm{Ma}$ ) followed by cooling to c. $330 \mathrm{Ma}$, coincident with the inversion of the basin at this time (Haines et al. 2001). Assuming a surface temperature of about $20^{\circ} \mathrm{C}$ at the time of inversion then we derive average thermal gradients in the basin of about $28-38^{\circ} \mathrm{C} / \mathrm{km}$. Using our unpublished conductivity measurements cited above, these data yield heat flows of c. $75-100 \mathrm{mWm}^{-2}$ during the late stages of basin evolution, comparable with the range of modern thermal gradients and somewhat higher than in the Tornquist zone in western Europe (Balling 1995).

In terms of potential variations in Moho temperature for the different settings we need to make certain assumptions about the source of the heat flow variation. If we are correct in attributing the differences in heat flow to variations in the heat production of the crust underlying the basin
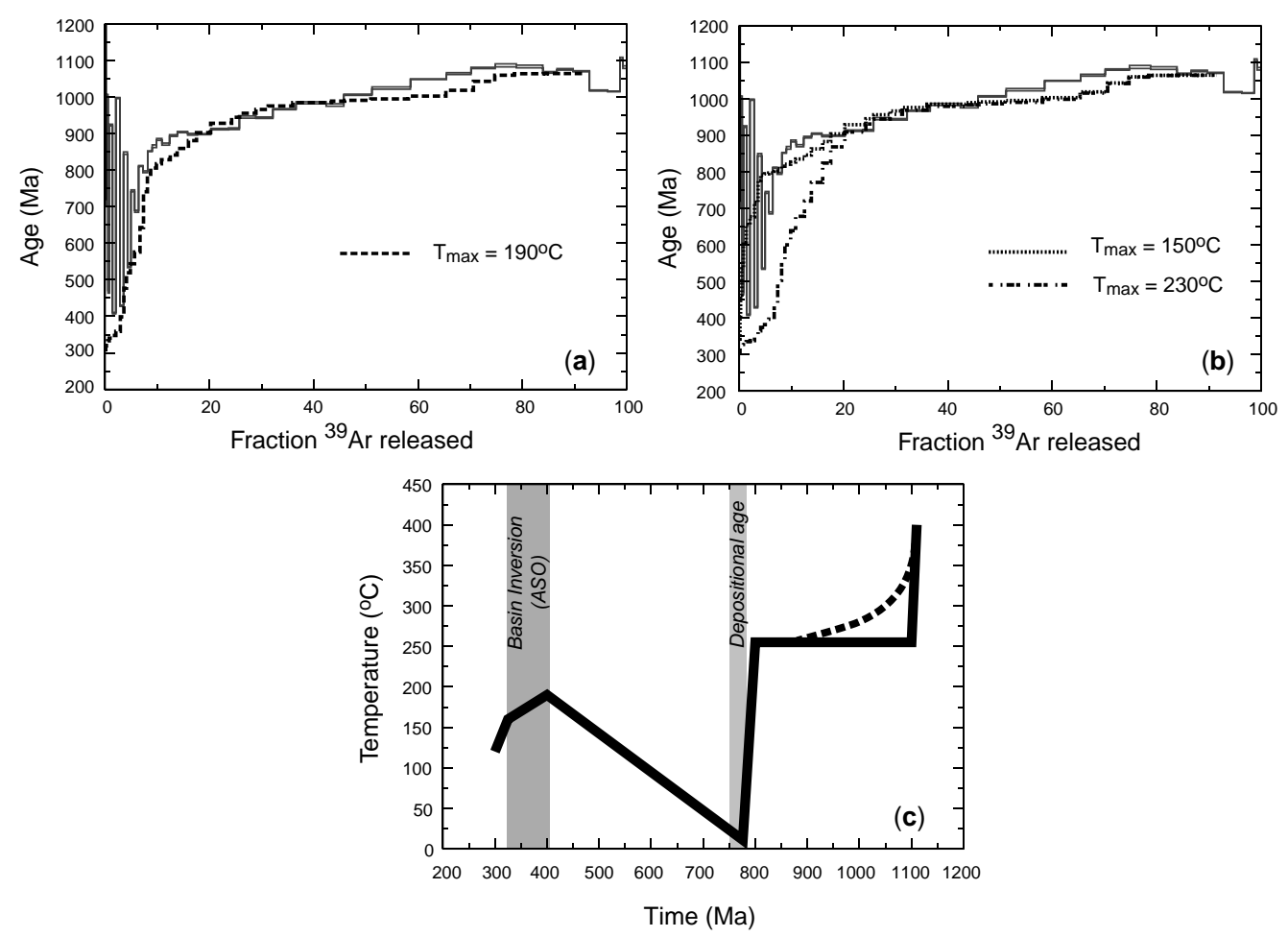

Fig. 5. ${ }^{40} \mathrm{Ar} /{ }^{39} \mathrm{Ar}$ age spectrum for K-feldspar 01-524 (a) laboratory age spectrum with best-fit model age spectrum, (b) laboratory age spectrum and model age spectra for post-depositional temperature maxima of $230^{\circ} \mathrm{C}$ and $150^{\circ} \mathrm{C}$. The poor fit to the laboratory data provides robust constraints on this portion of the cooling history. (c) Best-fit temperature time history corresponding to a maximum post-depositional temperature of $190^{\circ} \mathrm{C}$. Dashed line indicates alternative best-fit history for the higher temperature history. See Fig. 4 for the sample site and Appendix 1 for details of analytical methods and interpretation. 
then, following the simple formula introduced by Sandiford and McLaren (2002), the difference in temperature at or beneath the Moho is given by

$$
\Delta T_{m}=\frac{\Delta q_{c} h}{k}
$$

where $\Delta q_{c}$ is the difference in the integrated heat production of the crust (as, e.g., reflected in the surface heat flows), $h$ is the mean depth of the heat production and $k$ the thermal conductivity. Assuming a difference in heat production $\left(\Delta q_{c}\right)$ equivalent to $15 \mathrm{mWm}^{-2}$ (as suggested by the analysis above), $h=10 \mathrm{kms}$ (as is typical of the continents), and $k=2.7 \mathrm{Wm}^{-1} \mathrm{~K}^{-1}$ (as indicated by the above quoted conductivity), then we anticipate that temperatures at Moho depths might be as much as $50^{\circ} \mathrm{C}$ hotter beneath the Amadeus basin compared to the Tornquist zone. The effect of such temperature difference is significant, as in the temperature range $500-600^{\circ} \mathrm{C}$, a $10^{\circ}$ temperature rise results in approximately $10 \%$ reduction in bulk lithospheric strength at a given strain rate (Sonder \& England 1986).

\section{Thermal and compositional controls on rheological structuring of rifted crust}

At the lithospheric scale the long-term mechanical consequences of extension are potentially influenced by two distinct thermal and compositional effects (Fig. 6, see Sandiford 1999). Firstly, due to density contrasts between basin-filling sediments and extended crust there

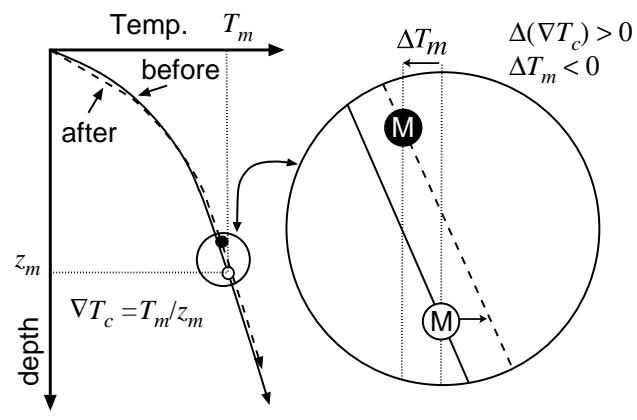

Fig. 6. Schematic illustration of the long-term thermal effects of crustal extension and basin formation (adapted from Sandiford 1999). Long-term Moho temperature changes $\left(\Delta T_{m}\right)$ occur primarily due to Moho shallowing while changes in the thermal property structure of the overlying crust (mostly in the basin-fill), lead to changes in the average thermal gradient $\left(\nabla T_{c}=T_{m} / z_{m}\right)$. See text for further discussion. As is shown in Fig. 7, the characteristic long-term thermal response to basin formation $\left(\Delta T_{m}<0\right.$ and $\Delta\left(\nabla T_{c}\right)>0$ (see also Hansen \& Nielsen 2002). is a long-term reduction in the depth of the Moho following extension, with attendant Moho cooling $\left(\Delta T_{m}\right)$ dependant mainly on the steady-state thermal gradient in the deep crust (typically estimated at $5-10^{\circ} \mathrm{C} / \mathrm{km}$ ). The second effect relates to changes in the average crustal thermal gradient $\left(\nabla T_{c}\right)$ due to the thermal property structure (heat production and thermal conductivity) of the extended crust and associated basin-fill. The attenuation of heat production in the pre-existing crust during extension leads to long-term reductions in $\nabla T_{c}$, while the burial of this heat production beneath the basinfill leads to increases in $\nabla T_{c}$ (Sandiford 1999; Hansen \& Nielsen 2002; Sandiford et al. 2003).

There is a considerable range in the plausible thermal property structure of continental crust and basin-fill (Sandiford 1999). The large number of parameters that influence the thermal structure of continental crust implies there can be no unique thermal response of the continental crust to extension. Consequently, in order to demonstrate the plausible long-term thermal response, we use a Monte Carlo approach based on the thermal property parameter ranges outlined by Hansen and Nielsen (2002) and Sandiford et al. (2003), wherein further details can be found. Figure 7 shows the results of a Monte Carlo simulation (c. 4500 individual parameter sets) of thermally-mature extensional basins. The great proportion (c. 86\%) of modelled parameter sets result in an increase in thermal gradient beneath basins $\left(\Delta\left(\nabla T_{c}\right)>0\right)$, with the median value of $\left(\Delta\left(\nabla T_{c}\right) \sim 1^{\circ} \mathrm{C} / \mathrm{km}\right)$ implying that the upper mantle beneath the basin is significantly hotter (by around $30-40^{\circ} \mathrm{C}$ ) than the upper mantle at similar depths outside the basin. Despite this characteristic long-term increase in thermal gradient beneath basin centres, the great majority $(76 \%)$ of modelled parameter sets result in long-term Moho cooling $\left(\Delta T_{m}<0\right)$ reflecting the significant reduction in Moho depth accompanying the isostatic compensation of low-density sediment fill. Long-term changes in the thermal gradient $\left(\nabla T_{c}\right)$ beneath basins necessarily result in lateral heat flow, typically directed away from the basin centre because of the increase in the average thermal gradients beneath the basin. For $\Delta\left(\nabla T_{c}\right)>0$ such lateral heat flow directed away from basin centres results in Moho temperature maxima beneath basin margins (Hansen \& Nielsen 2002), where the Moho temperatures may be elevated by up to $20^{\circ} \mathrm{C}$, although typically by less than $5^{\circ} \mathrm{C}$.

The modelling results summarized in Figure 7 provide an important insight into the thermal structure beneath old, sediment-filled extensional basins. In particular, the lower crust and upper 


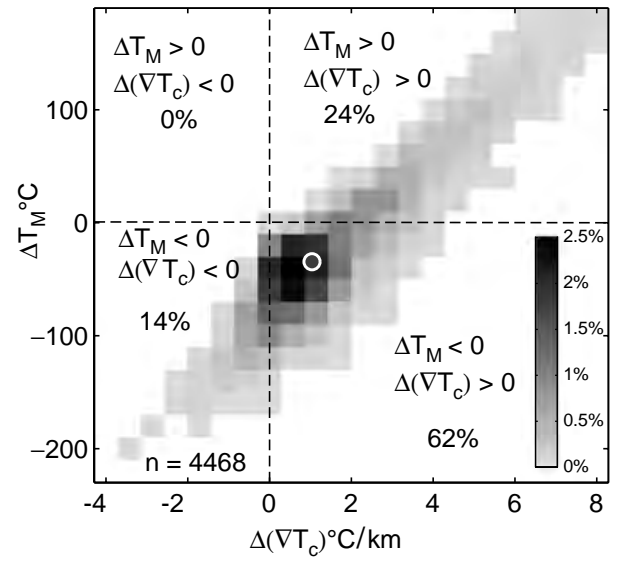

Fig. 7. Monte Carlo simulation of the long-term changes in thermal structure of extended continental crust on which a sedimentary basin has developed. The thermal structure is expressed in terms of the changes in Moho temperature $\left(\Delta T_{M}\right)$ and average crustal thermal gradient $\left(\Delta\left(\nabla T_{c}\right)\right)$. The parameter ranges for the 4468 individual parameter sets are the same as those employed by Hansen \& Nielsen (2002). Data are presented as a proportion of the total, binned in $20^{\circ} \mathrm{C} \times 0.57^{\circ} \mathrm{C} / \mathrm{km}$ boxes. The median value is illustrated by the circle, with $\Delta T_{M}=-34^{\circ} \mathrm{C}$ and $\Delta\left(\nabla T_{c}\right)=+1^{\circ} \mathrm{C} / \mathrm{km}$.

mantle beneath the basin centres is likely to be several tens of degrees hotter than material at identical depths outside the basin, while the Moho is likely to be several tens of degrees cooler beneath the basin. The hottest Moho temperatures are expected at the margin of the stretched crust, where the Moho is deep but close enough to the warm basin interior to 'feel' the effects of lateral heat flow.

\section{Lower crustal rheological expression in inverted basins: thermal-mechanical modelling}

\section{Background}

The characteristic thermal and compositional structure of old, stretched continental crust (i.e., $\Delta T_{m}<0$ and $\left.\Delta\left(\nabla T_{c}\right)>0\right)$ arguably provides a useful natural experiment for testing models of lower crustal rheology against natural patterns of deformation observed in inverted basins. We use a thermal property set that is close to the median configuration produced by the Monte Carlo simulation (with $\Delta T_{m}=-34^{\circ} \mathrm{C}$, $\left.\Delta\left(\nabla T_{c}\right)=+1{ }^{\circ} \mathrm{C} / \mathrm{km}\right)$, and contrast the style of inversion produced with rheological models appropriate to a 'jelly sandwich' and 'stiff crust' schematically represented in Figure 1. For the 'jelly sandwich' model the lower crust and mantle are characterized by a rheology appropriate to wet anorthosite (Shelton \& Tullis 1981) and wet dunite (Chopra \& Paterson 1981), respectively, while for the 'stiff crust' model the lower crust and mantle both have the rheological properties of wet dunite (but with densities appropriate to crust and mantle, respectively). In both cases, the upper crust is assumed to have a rheology appropriate to wet quartzite (Paterson \& Luan 1990). The response of basins to inversion is modelled using a coupled elasto-plasto-viscous rheology implemented in a thermo-mechanical fully Lagrangian finite element code using 4620 linear triangular elements. Details of the modelling approach are outlined below.

\section{Modelling methodology}

A two-dimensional thermo-mechanical continuum model is used to investigate the lithospheric response to compression. The lithospheric profile is initially $300 \mathrm{~km}$ long and $120 \mathrm{~km}$ deep, consisting of three different mineralogical layers of upper crust (wet quartzite), lower crust (wet anorthosite) and mantle (wet dunite). In the right half of the model the elsewhere $40 \mathrm{~km}$ thick crust is thinned to $24 \mathrm{~km}$, with $8 \mathrm{~km}$ of sediments resting on top (Fig. 8). The mechanical part of the model is founded on a fully Lagrangian formulation of the principle of virtual work (Green \& Zerna 1968; Budiansky 1969; Malvern 1969). The principle of virtual work is complemented by a set of constitutive relations enabling viscoelastic and plastic deformation. The viscoelastic deformation form simulates temperature and time-dependent ductile creep of solid rock mass and is based on a Maxwell relation stating additivity of elastic and viscous strain rates (Jaeger \& Cook 1969). While the elastic strain rates satisfy Hooke's law (Ranalli 1995), with Young's modulus at $10^{11} \mathrm{~Pa}$ and Poisson's ratio at 0.25 , the viscous strain rates satisfy the empirical Dorn equation relating effective strain rates and stress levels for steady state creep (Ranalli 1995). In this case, the associated viscosity, $\vartheta$, may be calculated by

$$
\vartheta=B \dot{\varepsilon}^{1 / n-1} \exp \left(\frac{Q}{n R T}\right)
$$

where $\dot{\varepsilon}$ is the effective visco-elastic strain rate, $T$ is absolute temperature, and $R=8.31 \mathrm{~J} /$ (mol K) is the ideal gas constant. $n, Q, B$, are experimentally derived creep parameters 


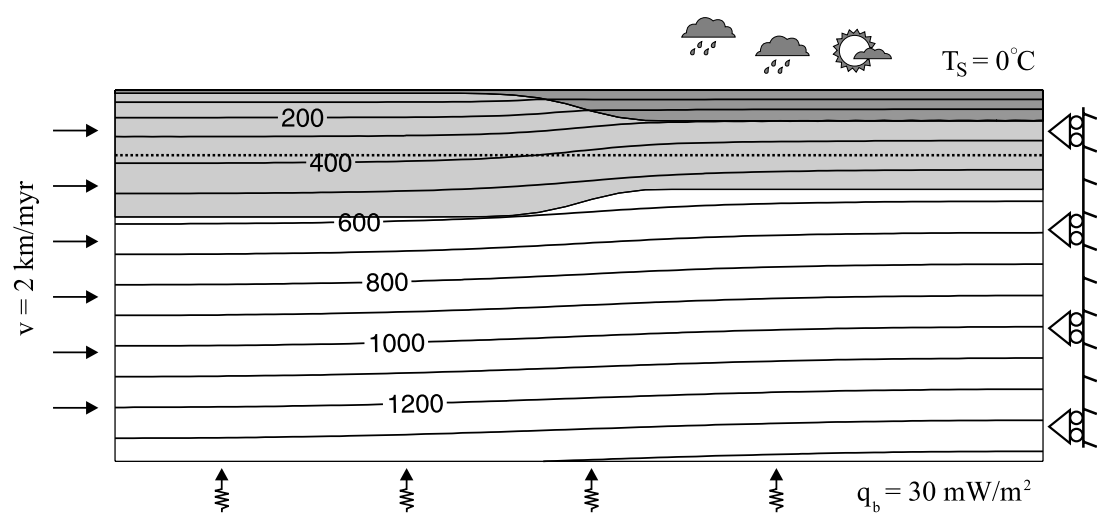

Fig. 8. Schematic of initial model conditions prior to inversion. The modelled domain is initially $300 \mathrm{~km}$ wide and $120 \mathrm{~km}$ deep. Inversion is imposed on the initial geometry with a thermally mature sedimentary basin above a constant thickness lithosphere. The dashed line indicates the approximate scale of the lithospheric stretching that would be needed to generate the initial basin.

(Chopra \& Patterson 1981; Shelton \& Tullis 1981) assumed only to depend on mineralogy.

When the yield stress of rocks is reached, the deformation form becomes visco-elastic-plastic, simulating brittle failure. The yield stress is derived from the pressure dependent DruckerPrager yield function (Khan \& Huang 1995):

$$
\sqrt{J_{2}}+\left(1-\lambda_{v}\right) \alpha(\phi) I_{1}=0
$$

approximating the conditions under which frictional Coulomb type materials fail (Byerlee 1978). Here $I_{1}$ is the first invariant of the Cauchy stress tensor and $J_{2}$ the second invariant of its deviatoric part. $\alpha(\phi)$ is a function of the angle of internal friction, $\phi$ (Khan \& Huang 1995):

$$
\alpha(\phi)=\frac{2 \sin (\phi)}{\sqrt{3}(3-\sin (\phi))}
$$

In Equation (3), $\lambda_{v}=0.4$ is the pore-fluid factor of near hydrostatic conditions (Sibson 1990). A nonassociated plasticity model (Vermeer \& De Borst 1984), where incompressible plastic strain rates $\hat{\eta}^{\mathrm{p}}$ are derived from the plastic potential, $\Omega$, is adopted:

$$
\hat{\eta}^{\mathrm{p}}=\frac{\partial \Omega}{\partial \sigma} \quad \text { where } \Omega=\sqrt{J_{2}}+\text { const } .
$$

The displacement and temperature fields are coupled through the temperature dependence of viscosity (Eqn. 2) and density. The latter is given by

$$
\rho=\rho_{0}\left(1-a_{v} T\right)
$$

where $\rho_{0}$ is density at $0^{\circ} \mathrm{C} . a_{v}=3.2 \times 10^{-5} \mathrm{~K}^{-1}$ is the volumetric expansion coefficient and $T$ is Celsius temperature.

In each model time step the temperature field is found by solving the transient heat transfer equation

$$
\rho c \dot{T}=\nabla \cdot(k \nabla T)-\rho c v \cdot \nabla T+A+W
$$

where $c$ is specific heat capacity, $k$ is conductivity, $A$ is radiogenic heat production rate, and $W$ is the viscous shear heating rate (Ranalli 1995; Regenauer-Lieb \& Yuen 1998). Material advection is represented by the relative velocity between material and grid points. On the mechanical model the temperature field is tracked using the same Lagrangian mesh and hence, here $v=0$. However, above the mechanical model the thermal mesh is extended to account for the deposition/erosion of sediments and, as such, the thermal mesh follows the topography formed by the changing sediment distribution. The relative velocity then represents the passive flow of material across the model surface (Hansen \& Nielsen 2003). The surface temperature is $0^{\circ} \mathrm{C}$, whilst at the model base the vertical heat flow is $30 \mathrm{~mW} / \mathrm{m}^{2}$. At the base of the mechanical model pressure conditions are imposed, allowing the entire model to move vertically under the influence of buoyancy forces. At the left vertical axis a constant kinematic boundary condition $(2 \mathrm{~km} / \mathrm{Ma})$ is imposed, compressing the model profile as the right vertical axis is fixed.

During the entire model evolution surface processes act to re-distribute sediments. These processes are modelled by a diffusion equation, with a source term enabling the transport of 
sediments to and from the model profile. The transport equation is written

$$
\dot{h}=\nabla \cdot(\kappa \nabla h)+\dot{s}(w)
$$

$\kappa=200 \mathrm{~km}^{2} / \mathrm{Ma}$ is the diffusivity of topography, $h$, and $\dot{s}(w)$ is a linear function of water depth. In the present study the last term is chosen so that any accommodation space created is immediately filled by sediments. Isochron markers record the chronological evolution of the basin fill by effectively representing stratigraphic boundaries. The porosity of sediment decreases with burial according to $\phi=\phi_{0} \exp (z / 2 \mathrm{~km})$, where $\phi_{0}$ is surface porosity and $z$ is maximal burial depth. All other parameters are listed in Table 1. The bulk of the sediment, which is present at the post-rift stage of the model start, is included in the thermo-mechanical model, whilst the sediment accumulating during the model evolution is directly included in the thermal model only. However, the redistribution of sediments during the model evolution influences the mechanical model as passive vertical loads.

\section{Modelling results}

In the 'jelly sandwich' lithosphere, lateral variations in the strength of the lithosphere are governed primarily by the temperature of the uppermost mantle, immediately below the Moho (Sonder \& England 1986). Because vertical thermal gradients are much greater than lateral gradients, variations in Moho depth are therefore crucial, with bulk lithospheric strength varying inversely with crustal thickness. With regard to a characteristic old extensional basin geometry with Moho shallowed beneath the centre of the basin, the lithosphere is strongest beneath the basin centre, and weakest along the outer margin of the basin. Consequently, in-plane compression will localize inversion in the vicinity of the basin margin (Fig. 9a). Deformation occurs in a confined zone that shows distinct localization in a zone propagating up through the crust as a basin verging ramp. Erosion focused on this marginal uplift sheds reworked sediment towards the basin interior, as well as away from the basin margin into the hinterland. Reworked sediment trapped within the basin interior produces a distinctive off-lapping succession progressively restricted towards the internal zones of the underlying rift basin.

In our 'stiff crust' lithosphere, the depth and temperature of the Moho is irrelevant to the rheological response of the lithosphere, and the thermal gradient is the primary control on the bulk lithospheric strength distribution. Because the modelled basin has higher average thermal gradients beneath the basin centre, in-plane compression necessarily localizes deformation beneath basin centres. The numerical simulation (Fig. 9b) produces diffuse strain rate gradients around a broad zone of distributed inversion. Erosion of the inverted domain sheds reworked sediment towards the basin foreland, potentially producing secondary marginal basins, outboard of the primary extensional basin. Structural asymmetry, albeit weak, verges from the basin centre towards the foreland. While not explicitly considered in the models shown here, localization phenomenon due to plastic instabilities should be expected to localize deformation in basin interiors and show a more abrupt transition between the inverted domain and the surrounding crust.

\section{Discussion}

Given the extraordinary temperature and mineralogical sensitivity of rheological flow laws pertinent to lithospheric deformation, it seems entirely reasonable that the mechanical response of the lithosphere will vary significantly as a function of its thermal regime and composition. It would therefore be unwise to suggest that the inversion of continental lithosphere can be characterized by the one uniform mode. Indeed, one of the paramount challenges in geodynamics is the understanding of how variations in the mechanical response to external forcing affect the final form and architecture of deformed continental crust. With this in mind, our models for

Table 1. Rheological and thermal parameters used in numerical models

\begin{tabular}{llcccc}
\hline Parameter & Symbol [units] & Upper crust & Lower crust & Upper mantle & Sediment \\
\hline Angle of internal friction & $\phi$ & 30 & 30 & 30 & 30 \\
Thermal conductivity & $k[\mathrm{~W} / \mathrm{m} / \mathrm{K}]$ & 3.0 & 2.3 & 4.0 & 2.0 \\
Specific heat & $c[\mathrm{~J} / \mathrm{kg} / \mathrm{K}]$ & 850 & 900 & 1000 & 900 \\
Heat production rate & $A\left[\mu \mathrm{W} / \mathrm{m}^{3}\right]$ & 1.3 & 0.3 & 0.01 & 1.0 \\
Creep parameter & $\mathrm{n}$ & 3.10 & 3.20 & 4.48 & 3.10 \\
Creep parameter & $\mathrm{B}\left[\mathrm{MPa} \mathrm{s}{ }^{1 / \mathrm{n}}\right]$ & 208.0 & 12.28 & 0.2628 & 208.0 \\
Creep parameter & $\mathrm{Q}\left[\mathrm{kJ} / \mathrm{mol}^{3}\right]$ & 135 & 239 & 498 & 135 \\
Density & $\rho_{0}\left[\mathrm{~kg} / \mathrm{m}^{3}\right]$ & 2800 & 2900 & 3400 & 2300 \\
\hline
\end{tabular}


(a)

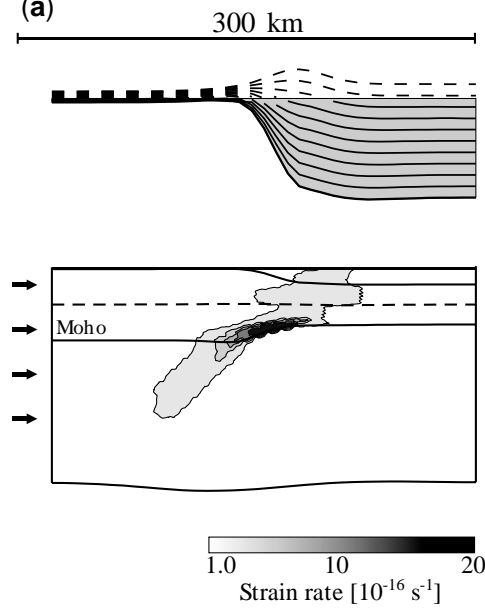

(b)
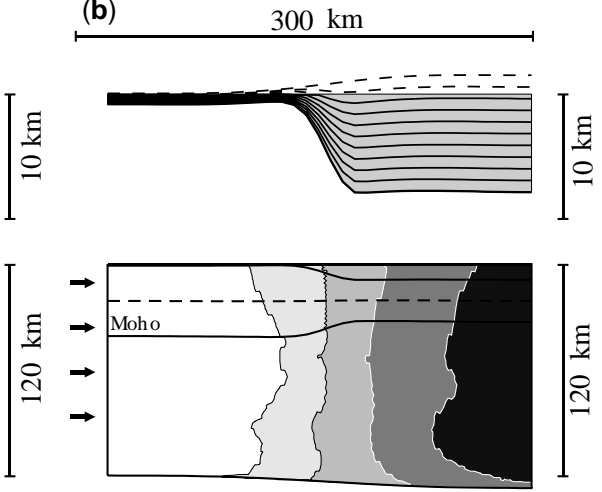

Fig. 9. Models of basin inversion styles predicted for different lower crustal rheology after $20 \mathrm{~km}$ of shortening. Upper panels show rift basin stratigraphy after inversion, while lower panels show the mean strain rate during the period of inversion. (a) The distribution of deformation for the 'jelly-sandwich' model. The weak lower crust and strong contrast across the Moho make the depth and temperature of the Moho critical determinants to the mechanical response.

(b) Identical modelling scenario but with a 'stiff crust' rheology (i.e., a relatively strong lower crust, with no contrast in strength across the Moho). Modelling techniques are based on a fully Langrangian elasto-plasto-viscous deformation code, as detailed in the text.

two end-member scenarios of lower crustal rheology provide an intriguing insight into some of the observed variations in the style of inversion in natural inverted basins. Our modelling suggests that the characteristic response of basins in inversion, producing inversion along the central basin axis (Figs 2 and 9b), is consistent with there being little rheological sensitivity to the position of the Moho. For standard thermal regimes, where steady-state Moho temperatures are expected to be no greater than $c .500^{\circ} \mathrm{C}$, this may therefore reflect the characteristic strong lower crustal rheological mode.

However, it is conceivable that, under different thermal regimes, the rheological contrast across the Moho plays a more prominent role. In support of this notion we can cite the unusual inversion record of Neoproterozoic basins in central Australia (Figs 3 and 4), where Palaeozoic inversion was at least partly localized along the margins of much older (>200 Ma) extensional basins. Here, the inversion structures verge towards basin interiors, similar to Figure 9a, with reworked sediment shed towards the interior of the inverted basins. As such, this central Australian style of inversion is consistent with a more prominent rheological contrast across the Moho. This analysis suggests that the thermal regime provides a principal control on the rheological structure of the lower crust, with the observed natural variation in inversion styles reflecting, at least in part, variations in the rheological state of the lower crust.
The model results we have presented show how thermal and compositional structuring of the lithosphere can lead to distinctive patterns of strain localization at the lithospheric scale, without appealing to strain-dependent weakening mechanisms. Many studies have shown that strain-dependent weakening is of fundamental importance to the behaviour of the continental lithosphere, and an important challenge is to establish the relative importance of the various localization mechanisms. With regard to this, our analysis suggests that the rheological structuring of the lithosphere associated with changes in Moho temperature of order $10^{\circ} \mathrm{C}$ is comparable to, if not more significant than, the rheological structuring associated with strain-dependent weakening processes during basin formation.

\section{Appendix 1. ${ }^{40} \mathrm{Ar} /{ }^{39} \mathrm{Ar}$ thermochronology}

K-feldspar 01-524 was irradiated for 480 hours in the Australian Nuclear Science and Technology Organization HIFAR reactor, NSW. The sample was subject to a series of 43 steps between $450^{\circ} \mathrm{C}$ and $1450^{\circ} \mathrm{C}$. The gas released was analyzed using a VG Isotech MM3600 gas source mass spectrometer with a sensitivity of $3.5 \times 10^{-17} \mathrm{~mol} / \mathrm{mV}$ (This data is available online at http://www.geolsoc.org.uk/ SUP18240. A hardcopy can be obtained from the Society Library.). The resultant ${ }^{40} \mathrm{Ar} /{ }^{39} \mathrm{Ar}$ age spectrum was interpreted using the multiple-diffusion-domain method assuming 
that argon release is by a thermally activated diffusion process (Lovera et al. 1989; Richter et al. 1991). We computed a distribution of activation energies and domain length scales (volume fraction and effective size) using eight slab-shaped domains (This data is available online at http://www.geolsoc.org.uk/ SUP18240. A hardcopy can be obtained from the Society Library.). The geological setting explicitly requires a reheating history associated with basin formation and we are able to calculate the best-fit temperature-time paths by inputting trial thermal histories and minimizing the differences between the laboratory and modelled-age spectra by iteration. Elsewhere (McLaren et al. 2002) we have shown that K-feldspar MDD modelling can be used to recover robust thermal histories from Australian Neoproterozoic basins, and that paper contains a rigorous discussion of our approach and the problems that need to be addressed to demonstrate that this approach yields meaningful results. The ${ }^{40} \mathrm{Ar} /{ }^{39} \mathrm{Ar}$ age spectrum of the sample (from estimated palaeodepths of $5.1 \pm 0.2 \mathrm{kms}$ in the Areyonga formation; see location in Fig. 4) shows a distinctive monotonically increasing age gradient, which suggests that the sample started to accumulate argon around $1100 \mathrm{Ma}$, with final closure to argon loss occurring in the Palaeozoic (Fig. 5). The preservation of Neoproterozoic ages provides an important constraint on the post-depositional temperatures in the basin. Modelling produces good fits with slow cooling from $1100 \mathrm{Ma}$ until at least $900 \mathrm{Ma}$ (as indicated by the broad range of ages in this interval). A period of rapid cooling at around $900-800 \mathrm{Ma}$ is required to generate the sedimentary detritus by the inferred depositional age of the sediment (c. $780 \mathrm{Ma}$, Lindsay 1989). While excess argon in the early released gas precludes a robust reconstruction of the reheating history in the depositional interval 780-400 Ma, we are able to constrain the range of temperature experienced during this interval. The age spectrum requires a period of slow reheating from $780 \mathrm{Ma}$ to between 170 and $190^{\circ} \mathrm{C}$ at $400 \mathrm{Ma}$ at $c .0 .5^{\circ} \mathrm{C} / \mathrm{Ma}$ at broadly consistent with the depositional history of the overlying sedimentary pile (e.g., Haines et al. 2001).

This work was supported by ARC grants DP0209157 and F10020050 and by the ACcESS MNRF. Constructive comments from L. Gemmer, R. Stephenson and E. Eide, and S. Buiter have helped our preparation of the manuscript. Irradiation of K-feldspar 01-524 was undertaken by the Australian Nuclear Science and Technology Organization through the Australian Institute of Nuclear Science and Engineering.

\section{References}

Afonso, J. C. \& Ranalli, G. 2004. Crustal and mantle strengths in continental lithosphere: is the jelly sandwich model obsolete? Tectonophysics, 394, 221-232.

BALLING, N. 1995. Heat flow and thermal structure of the lithosphere across the Baltic Shield and northern Tornquist Zone. Tectonophysics, 244, 13-50.

Beaumont, C., Munoz, J. A., Hamilton, J. \& Fullsack, P. 2000. Factors controlling the Alpine evolution of the central Pyrenees inferred from a comparison of observations and geodynamical models. Journal of Geophysical Research, 105, $8121-8145$.

Brace, W. F. \& Kohlstedt, D. L. 1980. Limits on lithospheric strength imposed by laboratory experiments. Journal of Geophysical Research, 85, 6248-6252.

Buchanan, J. G. \& Buchanan, P. G. 1995. Basin Inversion. Geological Society, London, Special Publications, 88.

BUDIANSKY, B. 1969. Remarks on theories of solid and structural mechanics. In: LAVRENT'EV, M. (ed.) Problems of Hydrodynamics and Continuum Mechanics. SIAM, Philadelphia, 77-83.

Byerlee, J. D. 1978. Friction of rocks. Pure and Applied Geophysics, 116, 615-626.

Camacho, A., Hensen, B. J. \& Armstrong, R. 2002. Isotopic test of a thermally driven intraplate orogenic model, Australia. Geology, 30, 887-890.

Chopra, P. N. \& Paterson, M. S. 1981. The experimental deformation of dunite. Tectonophysics, 78, 453-473.

Cooper, M. A. \& Williams, G. D. 1989. Inversion Tectonics. Geological Society, London, Special Publications, 44.

England, P. \& Houseman, G. 1986. Finite strain calculations of continental deformation II: comparison with the India-Asia collision zone. Journal of Geophysical Research, 91, 3664-3676.

Goleby, B. R., Shaw, R. D., Wright, C., Kennett, B. L. N. \& LAMBECK, K. 1989. Geophysical evidence for 'thick-skinned' crustal deformation in central Australia. Nature, 337, 325-330.

GorTER, J. D. 1984. Source potential of the Horn Valley Siltstone, Amadeus basin. Australian Petroleum Exploration Association Journal, 24, 66-90.

Green, A. E. \& ZernA, W. 1968. Theoretical Elasticity. Oxford University Press, New York.

Haines, P., Hand, M. \& Sandiford, M. 2001. Palaeozoic syn-orogenic sedimentation in central and northern Australia: a review of distribution and timing with implications for the evolution of intracontinental orogens. Australian Journal of Earth Sciences, 48, 911-928.

Hansen, D. L. \& Nielsen, S. B. 2002. Does thermal weakening explain basin inversion, stochastic modelling of the thermal structure of sedimentary basins. Earth and Planetary Science Letters, 198, 112-127.

Hansen, D. L. \& Nielsen, S. B. 2003. Why rifts invert in compression. Tectonophysics, 373, 5-24.

JACKSON, J. A. 2002. Strength of the continental lithosphere: time to abandon the jelly sandwich? GSA Today, 12, 1-4. 
JAEGER, J. C. \& COOK, N. G. W. 1969. Fundamentals of Rock Mechanics. Chapman and Hall Ltd., London.

Khan, A. S. \& HuAng, A. 1995. Continuum Theory of Plasticity. John Wiley \& Sons Inc., New York.

KoRsch, R. J. \& LindsAY, J. F. 1989. Relationships between deformation and basin evolution in the intracratonic Amadeus Basin. Tectonophysics, 158, 5-22.

LAmBECK, K. 1983. Structure and evolution of the intracratonic basins of central Australia, Journal of the Royal Astronomical Society, 74, 843-866.

LINDSAY, J. F. 1989. Depositional controls on glacial facies associations in a basinal setting, late Proterozoic, Amadeus Basin, central Australia. Palaeogeography, Palaeoclimatology, Palaeoecology, 73, 205-232.

LindsAY, J. F. \& KoRsCH, R. J. 1991. The evolution of the Amadeus Basin, central Australia. In: KoRsCH, R. J. \& KennARD, J. M. (eds) Geological and Geophysical Studies in the Amadeus Basin, Central Australia. Bureau of Mineral Resources, Geology and Geophysics Australia Bulletin, 236, 7-32.

Lindsay, J. F., KoRsCH, R. J. \& WILfORD, J. R. 1987. Timing the breakup of a Proterozoic supercontinent: evidence from Australian intracratonic basins. Geology, 15, 1061-1064.

Lovera, O. M., Richter, F. M. \& Harrison, T. M. 1989. The ${ }^{40} \mathrm{Ar} /{ }^{39} \mathrm{Ar}$ thermochronometry for slowly cooled samples having a distribution of diffusion domain sizes. Journal of Geophysical Research, 94, 17917-17935.

Maggi, A., JaCKson, J. A., McKenzie, D. \& Priestley, K. 2000. Earthquake focal depths, effective elastic thickness, and the strength of the continental lithosphere. Geology, 28, 495-598.

MALVERN, L. E. 1969. Introduction to the Mechanics of a Continuous Medium. Prentice-Hall, Inc., New Jersey.

McKenzie, D. 1978. Some remarks on the development of sedimentary basins. Earth and Planetary Science Letters, 40, 25-32.

Mclaren, S., Dunlap, J., Sandiford, M. \& McDougall, I. 2002. The thermochronological record of extraordinary heat production at Mount Painter, South Australia: implications for tectonic reactivation of continental interiors. Tectonics, 10.1029/2000TC001275.

Mclaren, S., Sandiford, M., Hand, M., Neumann, N., Wyborn, L. \& Bastrakova, I. 2003. The Hot Southern Continent: Heat Flow and Heat Production in Australian Proterozoic Terranes. Geological Society, Australia, Special Publications, 22, 157-167.

Nielsen, S. B. \& Hansen, D. L. 2000. Physical explanation of the formation and evolution of inversion zones and marginal troughs. Geology, 28, 875-878.

PAterson, M. S. \& LuAn, F. C. 1990. Quartize rheology under geological conditions. In: KNIPE, R. \& RutTER, E. (eds) Deformation Mechanisms, Rheology and Tectonics. Geological Society, London, Special Publications, 54, 299-307.

RANALli, G. 1995. Rheology of the Earth. Chapman \& Hall, London.

Regenauer-Lieb, K. \& Yuen, D. 1998. Rapid conversion of elastic energy into shear heating during incipient necking of the lithosphere. Geophysical Research Letters, 25, 2737-2740.

Richter, F. M., Lovera, O. M., HARrison, T. M. \& Copeland, P. 1991. Tibetan tectonics from ${ }^{40} \mathrm{Ar} /{ }^{39} \mathrm{Ar}$ analysis of a single K-feldspar samples. Earth and Planetary Science Letters, 105, 266-278.

SANDIFORD, M. 1999. Mechanics of basin inversion. Tectonophysics, 305, 100-120.

SANDIFORD, M. 2002. Low thermal Peclet number intraplate orogeny in central Australia. Earth and Planetary Science Letters, 201, 309-320.

SAndiford, M. \& McLaren, S. 2002. Tectonic feedback and the ordering of heat producing elements within the continental lithosphere. Earth and Planetary Science Letters, 204, 133-150.

SAndiford, M., Frederiksen, S. \& Braun, J. 2003. The long-term thermal consequences of rifting: implications for basin reactivation. Basin Research, 15, 23-24.

Sandiford, M., Hand, M. \& Mclaren, S. 2001. Tectonic feedback, intraplate orogeny and the geochemical structure of the crust: a central Australian perspective. In: Miller, J., Holdsworth, R., BuICK, I. \& HAND, M. (eds) Continental Reactivation and Reworking. Geological Society, London, Special Publications, 184, 195-218.

Shaw, R. D., Etheridge, M. A. \& Lambeck, K. 1991. Development of the late Proterozoic to mid-Palaeozoic intracratonic Amadeus Basin in central Australia: a key to understanding tectonic forces in plate interiors. Tectonics, 10, 688-721.

Shelton, G. \& Tullis, J. 1981. Experimental flow laws for crustal rocks. EOS (Transactions), American Geophysical Union, 62, 396.

Sibson, R. 1990. Conditions for fault-value behaviour. In: KnIPE, R. J. \& Rutter, E. H. (eds) Deformation Mechanisms, Rheology and Tectonics. Geological Society, London, Special Publications, 54, 143-165.

SONDER, L. \& ENGLAND, P. 1986. Vertical averages of rheology of the continental lithosphere; relation to thin sheet parameters. Earth and Planetary Science Letters, 77, 81-90.

Stephenson, R. A. \& Cloetingh, S. 1991. Some examples and mechanical aspects of continental lithosphere folding. Tectonophysics, 188, 27-27.

Teyssier, C. 1985. A crustal thrust system in an intracratonic environment. Journal of Structural Geology, 7, 689-700.

Turner, J. P. \& Williams, G. A. 2004. Sedimentary basin inversion and intraplate shortening. Tectonophysics, 65, 277-304.

Vermeer, P. A. \& De Borst, R. 1984. Non-associated plasticity for soils, concrete and rock. Heron, 29, $1-62$.

Walter, M. R. \& Gorter, J. D. 1994. The Neoproterozoic Centralian Superbasin in Western Australia: the Savory and Officer Basins. In: Purcell, P. G. \& Purcell, R. R. (eds) The Sedimentary Basins of Western Australia. Proceedings Petroleum Exploration Society Australia Symposium, Perth, 851-864.

Walter, M. R., Veevers, J. J., Calver, C. R. \& GREY, K. 1995. Neoproterozoic stratigraphy of the Centralian Superbasin, Australia. Precambrian Research, 73, 173-195. 
Downloaded from http://sp.lyellcollection.org/ at Australian National University on August 27, 2014 